\title{
Structural and Optical Performance of ZnS Nanoparticles Synthesized via Chemical Route.
}

\author{
G. G. Ramteke ${ }^{1 *}$ A. S. Lanje ${ }^{2}$, D. M. Pimpalshende ${ }^{1}$ \\ ${ }^{1}$ Department of Physics, Dr. Ambedkar College. Chandrapur-442401, M. S. India \\ ${ }^{2}$ Department of Electronics, Dr. Ambedkar College, Chandrapur-442401, M. S. India \\ *Corresponding Author: ggramteke@gmail.com, Tel: 09420137739
}

Available online at: www.isroset.org

Received: 20/May/2018, Revised: 39/May/2018, Accepted: 15/Jun/2018, Published: 30/Jun/2018

\begin{abstract}
In this analysis, ZnS nanoparticles have been synthesized employing an easy chemical co-precipitation route using metal precursors and DMF $\left(\mathrm{CH}_{3}\right)_{2} \mathrm{NC}(\mathrm{O}) \mathrm{H}$ as a stabilizing agent. The obtained $\mathrm{ZnS}$ nanoparticles have been characterized through XRD, TEM, UV-Vis, FTIR and PL measurements. The foremost intense broad peaks in the diffraction outline reveal the crystalline character of the prepared material with the particle length is approximately $4.7 \mathrm{~nm}$. The optical band gap has been evaluated from the UV-Vis. absorption spectrum which is found to be about $3.95 \mathrm{eV}$. The blue swing in absorption spectra validates the formation of nanoparticles. Further, the TEM micrograph revealing the ZnS particles are in nano dimension. FTIR study has been carried out for the bond evaluation. The PL measurement shows the emission of colour in the blue area.
\end{abstract}

Keywords--- ZnS nanoparticles, XRD, TEM, optical band gap, FTIR, PL

\section{INTRODUCTION}

Semiconductor nanoparticles have attracted a lot of analytical curiosity due to their spectacular properties originating from quantum confinement impact [1-3]. Among the range of semiconductor nanoparticles, zinc sulphide $(\mathrm{ZnS})$ is a crucial II-VI category inorganic semiconductor due to its huge scope of applications which includes in solar cells, cathode-ray tubes (CRT), field emission display (FED), phosphors for a long time, flat panel display. The $\mathrm{ZnS}$ has additionally been used for electroluminescent devices and photodiodes in addition to catalysts. Further, the $\mathrm{ZnS}$ nanomaterials exhibit exceptional physical and chemical features compared with their bulk material [4-7]. Within the past decade, $\mathrm{ZnS}$ nanoparticles have been synthesized through numerous ways which might be divided into two categories: physical technique and chemical technique which encompass hydrothermal method, micro-emulsion technique, a sol-gel technique, chemical co-precipitation technique, sonochemical technique, microwave irradiation, wet chemical technique and solvothermal technique. The physical way needs high reaction temperature, extensive use of organic solvents, high expenditure of kit operation and sophisticated method management, whereas the chemical technique is easy, low priced and handy to perform. Therefore, the chemical co-precipitation technique is typically accustomed synthesizing the zinc sulphide (ZnS) nanoparticles [8-12]. ZnS may be commercially vital II-VI semiconductor having good optical band gap, rendering it awfully engaging material for optical application particularly in nanocrystalline type. The ZnS has two completely different crystal structures (zinc blend and wurtzite) each of those have same band gap energy and also the direct band structure.

In the present study, the straightforward and cheap method, chemical co-precipitation technique has been utilized to prepare $\mathrm{ZnS}$ nanoparticles. The optical properties of ready $\mathrm{ZnS}$ nanoparticles have been investigated. The XRD, TEM, UV-Vis, FTIR and PL techniques have been adapted to characterize the synthesized $\mathrm{ZnS}$ nanoparticles.

Organization of this research paper is done into five sections: Introduction, Related work, Materials and Methods, Results with Discussion and Conclusions. Introduction section provides the brief review of literature related to our present study. Related work section elaborates on some work done by various researchers on optical characterization of $\mathrm{ZnS}$ nanoparticles. Materials and methods section contains precursors and chemicals utilised for the synthesis of $\mathrm{ZnS}$ nanoparticles, details of 
experimental route and the characterizations techniques employed for the analysis of prepared $\mathrm{ZnS}$ nanoparticles by chemical co-precipitation technique. Results and Discussion section provides a brief details on the characterization of $\mathrm{ZnS}$ nanoparticles and the analysis. Conclusion section provides the major conclusions drawn from the results.

\section{RELATED WORK}

There are some reports on the structural and optical characterization of $\mathrm{ZnS}$ nanoparticles. Some of the related works done by various researchers are, S. K. Kulkarni et. al. 2001 [13] reported optical properties of chemically capped CdS, ZnS, ZnCdS nanoparticles. Qihua Xiong, et. al. 2004 [14] investigated optical properties of rectangular cross-sectional ZnS nanowires. Gopa Ghosh et. al. 2006 [15] reported synthesis and characterization of PVPencapsulated ZnS nanoparticles. J. P. Borah et. al. 2008 [16] studied optical and optoelectronic properties of $\mathrm{ZnS}$ nanostructured thin films. S. Farjami Shayesteh et. al. 2013 [17] have described about the effect of $\mathrm{pH}$ on the structural and optical properties of $\mathrm{ZnS}$ nanoparticles embedded in PVA matrix.

\section{MATERIALS AND METHODS}

\section{A. Experimental:}

$\mathrm{ZnS}$ nanoparticles have been synthesized using metal precursor, i.e. Zinc acetate $\left[\left(\mathrm{CH}_{3} \mathrm{COO}\right)_{2} \mathrm{Zn}, 2 \mathrm{H}_{2} \mathrm{O}\right]$ (A.R. Merck) and Sodium Sulphide $\left[\mathrm{Na}_{2} \mathrm{~S}, \mathrm{H}_{2} \mathrm{O}\right]$ (extra pure Loba Chemie) was used as a supply of sulphur. N-N Dimethyl Formamide (DMF) $\left(\mathrm{CH}_{3}\right)_{2} \mathrm{NC}(\mathrm{O}) \mathrm{H}$ (Merck) is employed as stabilizing agent. All the chemicals employed in this examination are of analytical chemical reagent (AR) grade and used with no further refining. The deionised water has been used as the solvent for all the solutions referred in this analysis.

0.1 M Zinc acetate solution was prepared by dissolving appropriate weight of zinc acetate in $100 \mathrm{ml}$ double distilled water and $0.1 \mathrm{M}$ sodium sulphide is likewise made in $100 \mathrm{ml}$ double distilled water. The ready zinc acetate solution was mixed with certain quantity of DMF and stir for 10 minutes. Then $100 \mathrm{ml}$ sodium sulphide solution was introduced in the aggregate drop with the aid of drop with constant stirring for 3 hours. This ends up in milky white solution. This solution is stored overnight. Later on that was washed with double distilled water many times in centrifugal machine and at last with acetone to remove the un-reacted molecules. The obtained product has been filtered and dried in vacuum oven at $60^{\circ}$ for 8 hours. The product are then crushed into fine powder and subsequently collected in a sample bottle for the characterization.

\section{B. Characterization of $\mathrm{ZnS}$ nanoparticles:}

The structural analysis of $\mathrm{ZnS}$ nanoparticles was carried out with the aid of the use of X-ray powder diffractometer (Model: $\mathrm{D}-8$ Advance) with $\mathrm{Cu}-\mathrm{K} \alpha$ radiation $(\lambda=0.15406$ $\mathrm{nm})$ scanning $2 \theta$ in the range $10^{\circ}-90^{\circ}$. The morphology of the prepared sample was examined through transmission electron microscopy (TEM) with Tecnai $20 \mathrm{G}^{2}$ (FEI) version make under $200 \mathrm{KV}$. A UV-Vis absorption spectrum was recorded using Jasco spectrometer, (Model V-770, Serial No. A013161801) for the wavelength range 200-1100 nm. FTIR spectra has been recorded the use of Bruker, Germany. Model: Vertex 70 with resolution 0.5 $\mathrm{cm}^{-1}$. PL spectra has been recorded the use of model: F7000 FL Spectrophotometer, Serial number: 2702-001.

\section{IV.RESULTS AND DISCUSSION}

\section{A. X-ray Diffraction Analysis}

The XRD pattern of synthesized $\mathrm{ZnS}$ nanoparticles is displayed in Figure-1. The XRD pattern of $\mathrm{ZnS}$ has three strong peaks at the angles $2 \theta=28.87^{\circ}, 48.03^{\circ}$, \& $56.81^{0}$ which may be well indexed to nanocrystallite with (111), (220) and (311) planes respectively of cubic $\mathrm{ZnS}$ crystal lattice that is well matched with JCPDS card file no. (800020). The broad diffraction peaks as seen within the XRD spectra is the direct consequence of the decreased particle length and attributed to the fine size of the grains of the sample. The broadness of the diffraction peaks suggests the formation of the nanoparticles and also the sharp peaks designates the crystalline character of the material [2].

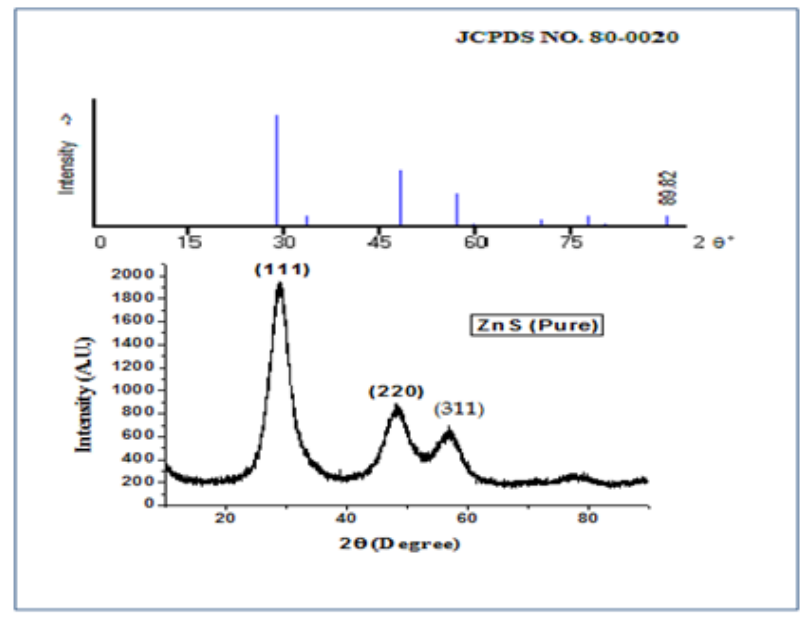

Figure. 1: XRD Pattern of ZnS nanoparticles 
From Full Width at Half Maximum (FWHM) of the foremost intense peak, the particle length has been estimated the usage of Debye-Scherer's rule [18]:

$$
\mathrm{D}=\frac{0.9 \lambda}{\beta \cos \theta}
$$

Wherein $\lambda=0.1541 \mathrm{~nm}$ is the wavelength of X-ray diffraction, $\beta$ is the FWHM in radian of the most intense XRD peak and $\theta$ is the angle of diffraction. The particle size for $\mathrm{ZnS}$ nanoparticles as calculated is determined to be $4.7 \mathrm{~nm}$. The lattice parameter ' $\mathbf{a}$ ' for $\mathrm{ZnS}$ nanoparticles is calculated via equation

$\mathbf{a}=\left[\frac{\lambda}{2 \sin \theta} \sqrt{h^{2}+k^{2}+l^{2}}\right] \AA$ and is found to be $\mathbf{5 . 3 6 6 4}$ $\AA$.

The d-spacing for cubic system for $2 \theta_{(111)}$ is calculated by using equation

$$
\mathbf{d}=\frac{a}{\sqrt{h^{2}+k^{2}+l^{2}}} \AA \text { and is found to be } 3.0982 \AA \text {. }
$$

\section{B. TEM Analysis}

The surface morphology of the sample is studied employing Transmission Electron Microscope (TEM). TEM photograph with SAED pattern is given in Figure 2(a). The TEM photograph reveals that the surface morphology of the prepared sample are assembled to form nanoparticles which forms crystalline aggregates consistently scattered above the whole surface. Further, the image shows particles are terribly slim and spherical in form.

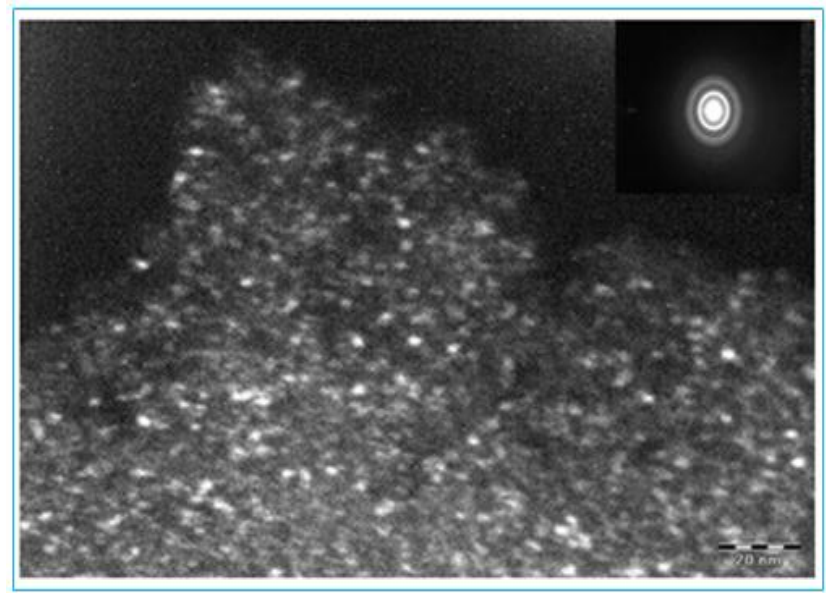

Figure 2(a):TEM image of $Z n S$ with SAED pattern

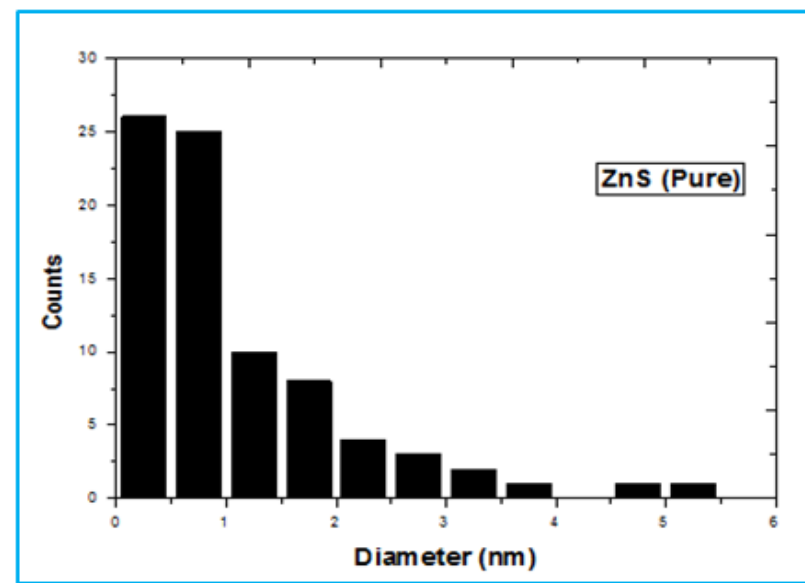

Figure 2(b): Size distribution histogram of $\mathrm{ZnS}$

The particle size distribution histogram is demonstrated by Figure-2(b). Approximately 81 numbers of particles were selected for calculating the particle size distribution. The typical particle size of the $\mathrm{ZnS}$ nanoparticles is determined to be about $4.2 \mathrm{~nm}$. This result is in sensible concurrence with the dimension estimated by XRD pattern and validates the formation $\mathrm{ZnS}$ nanoparticles.

\section{UV-Visible Absorption Spectra:}

The optical absorption performance of $\mathrm{ZnS}$ nanoparticles is displayed in Figure 3(a). The semiconductor nanoparticles show the amazing change in size quantization of the optical absorption spectra. As a result, the UV-Visible absorption analysis has been employed to look at the optical performance of nano regime particles. The synthesized material is of direct band gap temperament. In this analysis optical band gap has been calculated using Tauc equation. The Tauc's equlation is express as:

$$
(\alpha h v)^{1 / \mathrm{n}}=\mathrm{A}\left(\mathrm{h} v-\mathrm{E}_{\mathrm{g}}\right)
$$

Here $\alpha$ is absorption coefficient, $\mathrm{A}$ is constant and $\mathrm{E}_{\mathrm{g}}$ is band gap of material and the exponent $n$ depends on the nature of the transition. For direct allowed transition $n=1 / 2$, indirect allowed transition $\mathrm{n}=2$, direct forbidden transition $\mathrm{n}=3 / 2$, indirect forbidden transition $\mathrm{n}=3$. To determine the viable transitions, a graph of $(\alpha h v)^{2}$ against $h v$ is drawn and corresponding band gap is estimated from extending the straight part of the curve on hv axis. The direct band gap value of $\mathrm{ZnS}$ sample have been acquired from $(\alpha h v)^{2}$ Vs hv graph as represented in Figure 3(b) and is determined to be $3.95 \mathrm{eV}$. The bulk band gap of $\mathrm{ZnS}$ is $3.72 \mathrm{eV}$ as reported by earlier researchers [19-20]. The calculated band gap is more than the bulk band gap of $\mathrm{ZnS}$ $(3.72 \mathrm{eV})$ that is due to quantum confinement impact. The grain size of $\mathrm{ZnS}$ nanoparticles may be calculated using following Brus equation [21] 
$\mathbf{E}_{\mathrm{g}(\mathrm{nano})}=\mathbf{E}_{\mathrm{g}(\mathrm{bulk})}+\frac{h^{2}}{8 R^{2}}\left(\frac{1}{m_{e}^{*}}+\frac{1}{m_{h}^{*}}\right)-\frac{1.8 e^{2}}{4 \pi \epsilon_{0} \varepsilon_{r}}$

where $\mathrm{E}_{\mathrm{g} \text { (nano) }}=3.95 \mathrm{eV}, \mathrm{E}_{\mathrm{g} \text { (bulk) }}=3.72 \mathrm{eV}, m_{e}^{*}=0.25 \mathrm{~m}_{\mathrm{e}}$ is the effective mass of electron, $m_{h}^{*}=0.59 \mathrm{~m}_{\mathrm{e}}$ [22] is the effective mass of hole, $\mathrm{m}_{\mathrm{e}}$ is the free electron mass and $\mathrm{R}$ is the particle radius, $\varepsilon_{r}$ is the dielectric constant and $\epsilon_{0}$ is the permittivity of free space. The first factor in above equation suggests the confinement effect and the second term is the Coulomb term. The second term is small due to strong confinement and might be ignored [21], so that the particle length estimated to be $4.4 \mathrm{~nm}$.

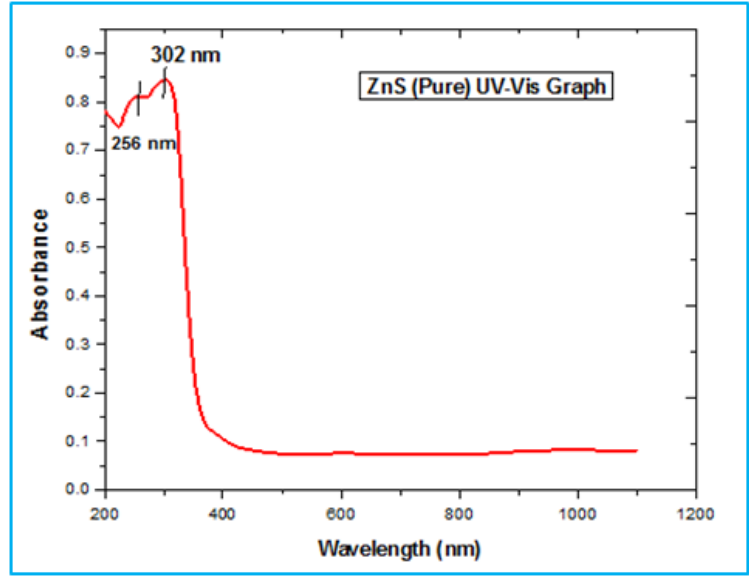

Figure 3(a): UV-Vis absorption spectra of ZnS

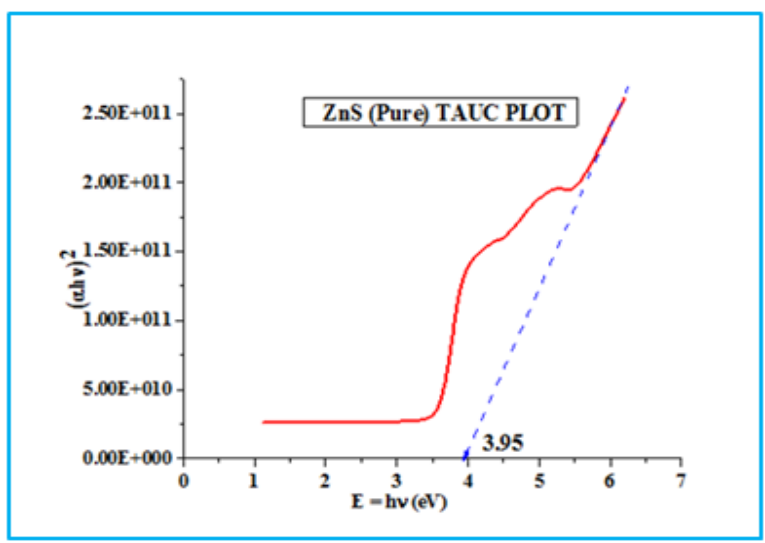

Figure 3(b): Tauc plot of ZnS nanoparticles

\section{FTIR Analysis}

The FTIR spectrum of pure $\mathrm{ZnS}$ sample recorded in the range of $400-4000 \mathrm{~cm}^{-1}$ for identification of the functional groups present in the prepared sample is shown in Figure 4. The sample has been prepared in the form of pellet with $\mathrm{KBr}$ medium.

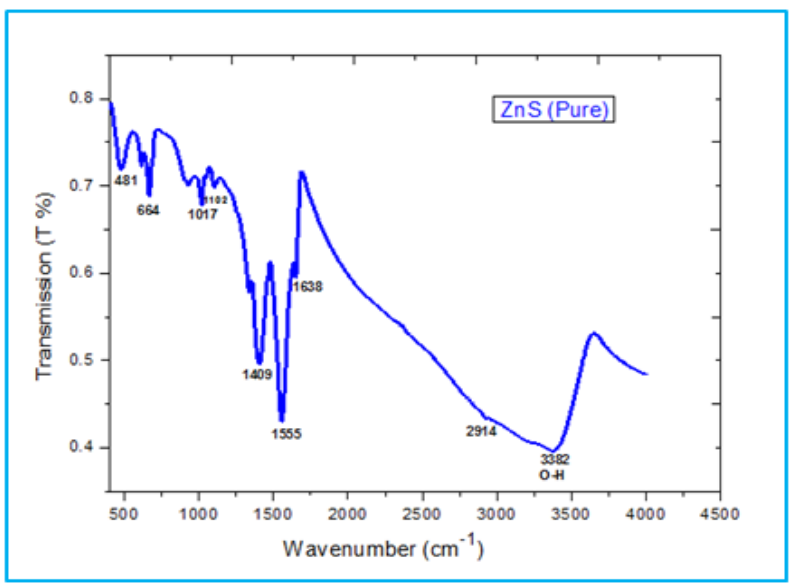

Figure 4: FTIR spectrum of ZnS nanoparticle

In the higher energy area the peak at $3389 \mathrm{~cm}^{-1}$ is quite broad and strong which might be assigned to $\mathrm{O}-\mathrm{H}$ stretching of absorbed water on the floor of $\mathrm{ZnS}$. The peak at $1555 \mathrm{~cm}^{-1}$ is assigned to $\mathrm{N}-\mathrm{H}$ deformation (Amide II band). The peak at $1409 \mathrm{~cm}^{-1}$ is assigned to $\mathrm{C}-\mathrm{N}$ stretching (Amide III band). The peak at $1017 \mathrm{~cm}^{-1}$ is assigned to C$\mathrm{O}$ stretching [23]. The peak at 481 and $664 \mathrm{~cm}^{-1}$ which have been attributed to vibrations of $\mathrm{Zn}-\mathrm{S}$ bond [24].

\section{E. PL Study}

Photoluminescence (PL) spectrum of pure $\mathrm{ZnS}$ sample measured at room temperature, excited at wavelength 405 $\mathrm{nm}$ is represented by Figure 5. This spectrum shows broad emission peak centred at around wavelength $492 \mathrm{~nm}$ signifying the emission of colour in blue area $[25,26]$; it is due to recombination of electrons at the sulphur vacancy donor level. Another peak of smaller intensity is observed at higher wavelength around $611 \mathrm{~nm}$ within the region of orange colour.

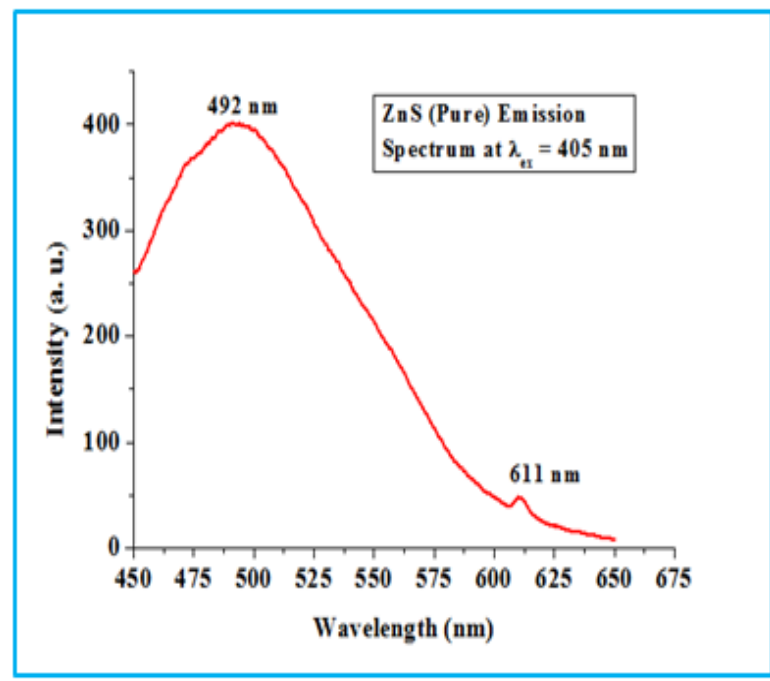

Figure 5: Emission spectrum of $\mathrm{ZnS}$ at $\lambda_{e x}=405 \mathrm{~nm}$ 


\section{CONCLUSIONS}

$\mathrm{ZnS}$ nanoparticles are successfully synthesized by simple co-precipitation method. The crystal structure and the grain size of the particles are determined using XRD which is also confirmed by TEM micrograph. Broad peaks in XRD pattern and blue shift in absorption maxima clearly indicates the formation of nanoparticles. TEM micrograph reveals the uniformly distributed fine particles, which form crystalline aggregates. UV-Vis absorption spectrum shows a blue shift indicating quantum confinement of charged particles. The presence of template on nanoparticles is confirmed by FTIR study. PL measurements show the emission of colour in blue region. Increased energy band gap due to nanoparticles size is competent in emitting light of wavelength in the blue range. Hence, prepared $\mathrm{ZnS}$ nanoparticles can be used in optical devices like LED, flat panel displays [27]. In future, we plan to study the effect of doping by some metal ions on the structural and optical behaviour of $\mathrm{ZnS}$ nanoparticles.

\section{ACKNOWLEDGEMENTS}

Authors express their sincere gratitude to the Director and Centre director, UGC-DAE CSR, Indore for providing the different instrumentation facilities. We are also grateful to Dr. Mukul Gupta for XRD, Dr. N. P. Lalla for TEM and Dr. U. P. Deshpande for FTIR measurements. We also wish to acknowledge Dr. R.R. Patil Institute of Science, Nagpur for PL measurements.

\section{REFERENCES}

[1] A. S. Lanje, S. J. Sharma, R. S. Ningthoujam, J-S Ahn and R. B. Pode, "Low temperature dielectric studies of zinc oxide ( $\mathrm{ZnO})$ nanoparticles prepared by precipitation method", Advanced Powder. Technology, Vol. 24, pp. 331-335, 2013

[2] S. D. Bompilwar, S. B. Kondawar, V.A. Tabhane, "Impedance study of nanostructure cadmium sulphide and zinc sulphide", Archives of Applied Science Research, Vol. 2, Issue. 3, pp. 225230, 2010

[3] R. P. Pawar, "Structural and Optical Properties of Chemically synthesized ZnS Nanoparticles", Oriental Journal of Chemistry, Vol. 29, Issue. 3, pp. 1139- 1142, 2013

[4] Khalid T. Al-Rasoul, Nada K. Abbas, Zainb J. Shanan, "Structural and optical characterization of $\mathrm{Cu}$ and $\mathrm{Ni}$ doped $\mathrm{ZnS}$ nanoparticles", International Journal of Electrochemical Science, Vol. 8, pp. 5594-5604, 2013

[5] B. S. Rema Devi, R. Raveendran and A. V. Vaidyan, "Synthesis and Characterization of Mn2 + -doped ZnS Nanoparticles", Pramana- journal of physics, Vol. 68, Issue. 4, pp. 679-687, 2007

[6] Ravi Sharma, "Studies on thermoluminescence glow curves of Mn doped ZnS nanoparticles", Recent Research in Science and Technology, Vol. 4, Issue. 8, pp. 34-35, 2012

[7] J. Taghavian and P. Hossein Khanai, "Synthesis and Thermo luminescence properties of $\mathrm{ZnS}$ Nanoparticles", International Journal of Nano Dimensions, Vol. 2, Issue. 2, pp. 125-127, 2011
[8] A. S. Lanje, R. S. Ningthoujam, S. J. Sharma, R. B. Pode, "Luminescence and electrical resistivity properties of cadmium oxide nanoparticles", Indian Journal of Pure \& Applied Physics, Vol. 49, pp. 234-238, 2011

[9] A. S. Lanje, S. J. Sharma, R. B. Pode, R. S. Ningthoujam,"Synthesis and Optical Characterization of Copper oxide Nanoparticles", Advances in Applied Science Research, Vol. 1, Issue. 2, pp. 36-40, 2010

[10] D. Ayodhya, M. Venkatesham, A. S. Kumari, K. G. Mangatayaru and G. Veerabhadram, "Synthesis, characterization of $\mathrm{ZnS}$ nanoparticles by coprecipitation method using various capping agentsphotocatalytic activity and kinetic study", IOSR Journal of Applied Chemistry, Vol. 6, Issue. 1, pp. 01-09, 2013

[11] SHE Yuan-yuan, Yang Juan and QIU Ke-qiang, "Synthesis of ZnS nanoparticles by solid-liquid chemical reaction with $\mathrm{ZnO}$ and $\mathrm{Na} 2 \mathrm{~S}$ underasonic",

Trans. Nanoferrous Metal Society of China,Vol. 20, pp. 211-215, 2010

[12] Baibaswata Bhattacharjee and Chung-Hsin Lu, "Multicolor luminescence of undoped zinc sulphide nanocrystalline thin films at room temperature", Thin Solid Films, Vol. 514, pp. 132-137, 2006

[13] S. K. Kulkarni, U. Winkler, N. Deshmukh, P. H. Borse, R. Fink and E. Umbach, "Investigation on chemically capped CdS, $\mathrm{ZnS}$, and $\mathrm{ZnCdS}$ nanoparticles", Applied Surface Science, Vol. 169-170, pp. 438-446, 2001

[14] Qihua Xiong, G. Chen, J. d. Acrod, X. Liu et. al., "Optical properties of rectangular cross-sectional ZnS nanowires", Nano Letters, Vol. 4, Issue. 9, pp. 1663-1668, 2004

[15] Gopa Gosh, Milan Kanti Naskar, Amitava Patra, and Minati Chatterjee, "Synthesis and characterization of PVPencapsulated ZnS nanoparticles", Optical Materials, Vol. 28, pp. 1047-1053, 2006

[16] J. P. Borah and K. C. Sharma, "Optical and optoelectronic properties of $\mathrm{ZnS}$ nanostructured thin films", ACTA PHYSICA POLONICA A, Vol. 114, Issue. 4, pp. 713-719, 2008

[17] S. Farjami Shayesteh, S. Kolahi and Y. Azizian-Kalandarragh, "Effect of $\mathrm{pH}$ on the structural and optical properties of $\mathrm{ZnS}$ nanoparticles embedded in PVA matrix", Indian Journal of Pure and Applied Physics, Vol. 51, pp. 780-783, 2013

[18] P. K. Mochahari, "Investigation of structural and spectroscopic properties of nanostructured CdS films", International Journal of Scientific Research In Physics and Applied Sciences, Vol. 5, Issue 6, pp. 1-6, 2017

[19] A. Yakoubi, T. B. Chaabane, A. Aboulaich, R. Mahiou, L. Balan, G. Medjahdi and R. Schneider, "Aqueous synthesis of $\mathrm{Cu}$-doped $\mathrm{CdZnS}$ quantum dots with controlled and efficient photoluminescence", Journal of Luminescence, Vol. 175, pp. 193-202, 2016

[20] C. S. Pathak and M. K. Mandal, "Optical properties of Mn2+ doped ZnS Nanoparticles", Asian Journal of Chemistry, Vol. 23, Issue. 10, pp. 4655-4658, 2011

[21] U. S. Senapati, D. K. Jha and D. Sarkar, "Green synthesis and characterization of ZnS nanoparticles", Research Journal of Physical Sciences, Vol. 1, Issue. 7, pp. 1-6, 2013

[22] Ageeth A. Bol, Joke Ferwerda, Jaap A. Bergwerff and Andries Meijerink, "Luminescence of nanocrystalline $\mathrm{ZnS}: \mathrm{Cu} 2+$ ", Journal of Luminescence, Vol. 99, pp. 325-334, 2002

[23] Joseph B. Lambert, et al., "Introduction to Organic Spectroscopy", Macmillan Publication, New York, pp. 174-177, 1987

[24] Sobia Dilpazir, Mohammad Siddiq and Azhar Iqbal, "Synthesis of Zinc Sulphide Nanostructures by CoPrecipitation: Effect of doping on Electro-optical Properties", 
Kenkyu Journal of Nanotechnolgy and Nanoscience., Vol. 1, pp. 34-39, 2015

[25] A. Tiwar, S. J. Dhoble and R. S. Kher, "Influence of thiol capping on the photoluminescence properties of L-cysteinemercaptoethenol-and mercaptopropionic acid-capped $\mathrm{ZnS}$ nanoparticles", Luminescence, Vol. 30, pp. 1148-1152, 2015

[26] Edgar Mosquera and Nicolas Carvajal, "Low temperature synthesis and blue photoluminescence of $\mathrm{ZnS}$ submicronparticles", Materials Letters, Vol. 129, pp. 8-11, 2014

[27] Akihiko Yoshikawa, Hiroyuki Matsunami and Yasushi Nanishi; "Wide Band gap Semiconductors", Book, ISBN- 9783-540-47235-3(online), pp. 1-24, 2007

\section{AUTHORS PROFILE}

Mr. G. G. Ramteke obtained B.Sc degree in 1995 \& M. Sc. (Physics) in 1997 from RTM Nagpur University, Nagpur, (MS), India. He is working as Assistant Professor in Dr. Ambedkar College of Arts, Commerce \& Science, Chandrapur (M. S.), India, since February 2000. He obtained M. Phil. Degree in Physics in 2008 from Periyar University, Salem (T. N.). Currently, he is doing $\mathrm{Ph}$. D. from Gondwana University, Gadchiroli, (M. S.), India. He has published three papers in International Journals. His area of research is Synthesis and Optical Characterization of some Semiconducting Nanoparticles.

A. S. Lanje obtained his Masters degree

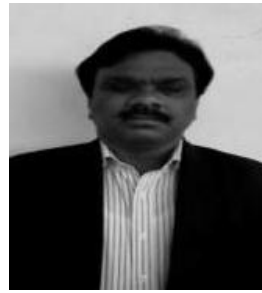
in Electronics in the year 1991 from RTM Nagpur University, Nagpur, India. He is honoured with $\mathrm{Ph}$. D. degree from the same University in November 2010. He has published more than 15 research papers in national \& international reputed journals. Also, he has published one book from Lambart publication, Germany. $\mathrm{He}$ is working as Associate Professor in the department of Electronics, Dr. Ambedkar College of Arts, Commerce \& Science, Chandrapur (M. S.), India. He is member of the BOS in Electronics; RTM Nagpur University, Nagpur and Gondwana University, Gadchiroli. His area of research is Material Science, Nanoelectronics and Nanosensors. Currently, four students are perusing under his supervision.

D. M. Pimpalshende passed B. Sc.in 1990 and obtained master's degree in Physics in the year 1992 from RTM Nagpur University, Nagpur. He received $\mathrm{Ph}$. D. degree from the same University in 2015. He obtained M. Phil. Degree in Physics in

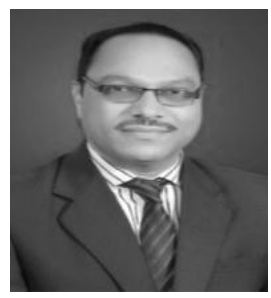
2008 from Periyar University, Salem (T. N.) His area of interest is the Synthesis and Characterization of luminescence nanomaterials for lighting applications. He has published more than 12 research papers in the reputed national and international journals. He is the member of BOS in Physics, Gondwana University, Gadchiroli (M.S.), India. $\mathrm{He}$ is Member of
Intrenational Association of Advanced Materials; Life Member of Vishwashanti Multipurpose Society; Life Member of N. H. Research Journal of Multidisciplinary Studies and life member of Luminescence Society of India (LSI). 